\title{
DRONE APLICADO NA AGRICULTURA DIGITAL
}

\author{
DRONE APPLIED IN DIGITAL AGRICULTURE \\ Bruno Henrique Tondato Arantes ${ }^{1}$; Leticia Tondato Arantes ${ }^{2}$; Estevam Matheus Costa ${ }^{1}$; Matheus \\ Vinicius Abadia Ventura ${ }^{3}$ \\ ${ }^{1}$ Mestrando em Ciências Agrárias - Agronomia. Instituto Federal Goiano - Campus Rio Verde - bhtondatto@gmail.com \\ ${ }^{2}$ Mestranda em Engenharia Civil. Universidade Estadual Paulista-Campus Ilha Solteira - letondato@gmail.com; \\ ${ }^{3}$ Doutorando em Ciências Agrárias - Agronomia. Instituto Federal Goiano - Campus Rio Verde
}

\section{Info}

Recebido: 01/2019

Publicado: 03/2019

ISSN: 2595-6906

Palavras-Chave

Agricultura digital; drone; imagem

digital.

Keywords:

Agriculture digital; drone; digital

image.

\section{Resumo}

O aumento dos custos de insumos e da demanda pela busca da sustentabilidade no meio rural exigem melhorias na eficiência do uso de recursos na agricultura. A agricultura de precisão (AP) pode ser utilizada para tomar decisões temporais e espaciais de forma precisa aumentando a eficiência nas aplicações e um manejo sustentável. Logo esta pesquisa teve como objetivo avaliar algumas aplicações com o veículo aéreo não tripulado (VANT) na identificação de falhas de plantio, de linhas de plantio e da contagem de plantas da cultura de mandioca. Teve também como objetivo a identificação de plantas daninhas em uma área de préplantio. Os voos foram realizados entre as $10 \mathrm{~h} 00$ e as $14 \mathrm{~h} 00$, para evitar efeitos da sombra gerados pela inclinação do sol sobre os objetos. Uma alta sobreposição foi adotada para as fotografias utilizadas. A altura de voo definida para todos os modelos de câmeras, foi de 40 metros, já que as áreas a serem sobrevoadas eram pequenas. Quanto a contagem de plantas e o mapeamento das linhas e das falhas de plantio, elas foram elaboradas no QGIS 2.18, através do mosaico gerado pelo DroneDeploy. Elas foram obtidas por meio das ferramentas de vetorização do software. Os espaços foram contabilizados como falhas, quando tal espaço era o suficiente para alocar uma planta ou mais. Para o mapeamento das plantas daninhas se utilizou um índice de vegetação (IV) elaborado no QGIS 2.18, na qual se gerou a classe de solo exposto e de plantas daninhas em função da biomassa. Através da aplicação de herbicida com o mapa de plantas daninhas, é possível realizar a aplicação à taxa variável a fim de minimizar os custos, já que onde só possui solo exposto a aplicação não é efetivada. Além disso, o mapa também permite inferir os locais que necessitam de uma vazão maior em função da quantidade de biomassa das plantas daninhas. Quanto à identificação das falhas de plantio e contagem de plantas, ela permite aumentar a produtividade e realizar planejamentos de replantio.

\footnotetext{
Abstract

Increased input costs and the demand for sustainability in rural areas require improvements in the efficiency of resource use in agriculture. Precision agriculture (AP) can be used to make precise temporal and spatial decisions, increasing application efficiency and sustainable management. The objective of this research was to evaluate some applications with unmanned aerial vehicle (UAV) in the identification of planting faults, planting lines and counting of cassava plants. It also aimed to identify weeds in a pre-planting area. The flights were carried out between 10:00 am and 2:00 p.m., to avoid shadow effects generated by the sun's tilt over objects. A high overlap was adopted for the photographs used. The flight height set for all camera models was 40 meters, since the areas to be flown were small. Regarding the plant count and the mapping of the planting lines and failures, they were elaborated in QGIS 2.18 through the mosaic generated by DroneDeploy. They were obtained through the software vectorization tools. The spaces were counted as failures, when such space was enough to allocate a plant or more. For the weed mapping, a vegetation index (IV) elaborated in QGIS 2.18 was used, in which the class of exposed soil and weeds were generated as a function of the biomass. Through the application of herbicide with the map of weeds, it is possible to carry out the application at variable rate in order to minimize costs, since where only soil exposed the application is not effective. In addition, the map also allows to infer the sites that need a larger flow rate depending on the amount of weed biomass. Regarding the identification of planting failures and plant counts, it allows to increase productivity and to carry out replanting planning.
} 


\section{INTRODUÇÃO}

$\mathrm{O}$ aumento dos custos de insumos e da demanda pela busca da sustentabilidade no meio rural exigem melhorias na eficiência do uso de recursos na agricultura. Felizmente, em muitos casos, recursos como fertilizantes, água para irrigação, herbicidas, e entre outros, podem ser usados com eficiência quando aplicados análises espaciais e temporais em dados obtidos por meio de veículos aéreos não tripulados (VANTs) (FLEMING et al., 2000; FOLEY et al., 2011; BASSO et al., 2011).

A agricultura de precisão (AP) pode ser utilizada para tomar decisões temporais e espaciais de forma precisa. Convencionalmente são aplicados fertilizantes ou produtos fitossanitários uniformemente em toda a lavoura. Contra estas técnicas, a AP pode aumentar a eficiência dos fertilizantes medindo o teor de nutrientes nas plantas e ajustando a taxa de aplicação de acordo com o necessário e o local. Nas plantas daninhas pode aumentar a eficiência dos herbicidas e diminuir custos com a aplicação de acordo com a localização e a densidade (CHRISTENSEN et al.,2009).

Em algumas culturas, como na cana de açúcar, o uso das geotecnologias permite a identificação de falhas de plantio para aumentar a produtividade e maximizar os custos por meio da adoção de técnicas eficientes de plantio, dentre elas, o plantio guiado pelos sistemas de navegação por GNSS (Global Navigation Satellite System). A identificação e a quantificação de falhas na lavoura permitem aumentar os lucros e a competitividade no mercado sucroalcooleiro quando o replantio feito dentro do timing da cultura (ALVES et al., 2015).

Em suma, com o sensoriamento remoto e a agricultura de precisão é possível quantificar o problema espacialmente e realizar um manejo direcionado a fim de solucionar o problema dentro do tempo da cultura, além de planejar as linhas de plantio a fim de maximizar a utilização da área e a logística dos equipamentos agrícolas. Ainda, através de uma aplicação pontual de herbicidas, é possível diminuir os custos de forma significativa e evitar tal agressão ao meio ambiente.

Logo esta pesquisa teve como objetivo avaliar algumas aplicações com o veículo aéreo não tripulado (VANT) na identificação de falhas de plantio, de linhas de plantio e da contagem de plantas da cultura de mandioca. Teve também como objetivo a identificação de plantas daninhas em uma área de pré-plantio.

\section{MATERIAL E MÉTODOS}

A presente pesquisa foi realizada dentro do município de Jales - SP por meio de um Drone DJI Phantom 4 advanced embarcado com uma câmera comum, conhecido como sensor RGB. Tal equipamento sobrevoou uma área de plantio de mandioca e de pré-plantio a uma altura de 100 metros, com $70 \%$ de sobreposição lateral e longitudinal das fotografias. A sobreposição lateral é requerida para prevenir falhas entre faixas consecutivas, como resultado da deriva, inclinações, variação de altura do voo e do comportamento do terreno. Além do mais com o uso de uma sobreposição lateral maior, evita-se de utilizar os bordos extremas das imagens, cuja distorção radial da lente costuma ser maior. Antes do voo o planejamento das linhas de voo foram elaboradas dentro do software DroneDeploy, na qual foi o mesmo programa utilizado para mosaicar as imagens capturadas.

Os voos foram realizados entre as $10 \mathrm{~h} 00$ e as 14h00, para evitar efeitos da sombra gerados pela inclinação do sol sobre os objetos. Condições de ausência de nuvens é essencial para a obtenção de futuros resultados estatísticos condizente com a real situação do dossel das plantas analisadas nas imagens, 
apesar de em algumas situações as condições climáticas não permitir.

A sobreposição longitudinal é importante para a construção de mosaicos, geração de pontos de apoio por foto triangulação de imagens e a obtenção da estereopares. Recomenda em voos convencionais uma sobreposição entre 60 e $80 \%$.

Quanto a contagem de plantas e o mapeamento das linhas e das falhas de plantio, elas foram elaboradas no QGIS 2.18, através do mosaico gerado pelo DroneDeploy. Elas foram obtidas por meio das ferramentas de vetorização do software. Os espaços foram contabilizados como falhas, quando tal espaço era o suficiente para alocar uma planta ou mais.

Para o mapeamento das plantas daninhas se utilizou um índice de vegetação (IV) elaborado no QGIS 2.18, na qual se gerou a classe de solo exposto e de plantas daninhas em função da biomassa. Tal IV é dado pela seguinte expressão matemática:

SAVIGreen $=(G-R) /(G+R-B)$,

sendo $G$ a banda do verde, $R$ a banda do vermelho e $B$ a banda do azul.

\section{RESULTADOS E DISCUSSÕES}

Nos tempos modernos, o sensoriamento vem ocupando cada vez mais espaço nas diversas culturas agrícolas. Um exemplo é na contagem de plantas por meio de veículos aéreos não tripulados, do qual em um curto intervalo de tempo permite obter o número de indivíduos com precisão. Tal método permite por meio das falhas de plantio, realizar um planejamento para o replantio, de maneira a quantificar o número de plantas a serem utilizadas para estimar custos, além de permitir quantificar o aumento de lucro com o aumento do número de plantas. O sensoriamento remoto também permite a medição do tamanho de copa.

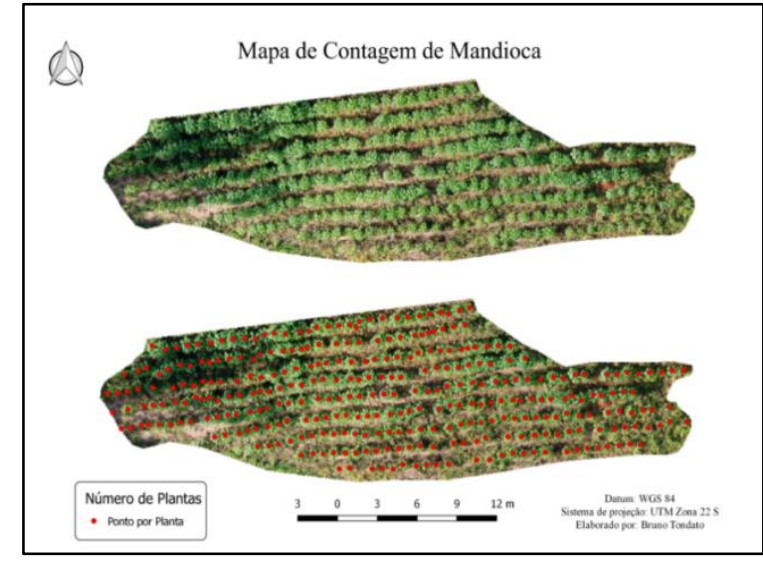

Figura 1 - Contagem de plantas. Fonte: $\mathrm{O}$ autor

$\mathrm{Na}$ cultura de mandioca a contagem é facilitada quando a planta está em um estágio mais precoce, uma vez que quando em um estágio vegetativo mais avanço tende a juntar as copas dificultando a contagem (Figura 1). Porém, em culturas como de citros a contagem é possível em qualquer época.

As falhas de plantio, ao contrário da contagem podem ser realizadas em qualquer tipo de cultura sem dificuldades. Através das identificações das falhas é possível estimar o quanto de produtividade o talhão está perdendo, uma vez que se pode estimar a porcentagem de falhas. No caso da mandioca, foram encontradas 13 falhas, com algumas delas sendo de até duas plantas. $\mathrm{O}$ número de falhas foi em torno de $4 \%$ nesta área da pesquisa, mas pode chegar a alguns casos em até 15\% ou mais (Figura 2).

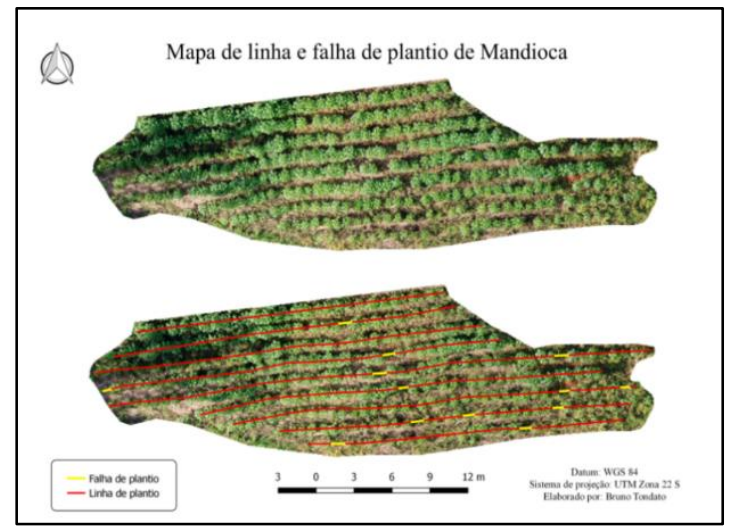

Figura 2 - Falhas de plantio. Fonte: $\mathrm{O}$ autor 
No caso da identificação de plantas daninhas por meio de imagens aéreas, esta técnica foi eficiente, tal que através da utilização do índice de vegetação SAVIGreen permitiu georreferenciar todas as plantas daninhas presente na área de estudo, porém não permitiu diferenciar uma espécie da outra (Figura 3). Tal índice foi utilizado por trazer bons resultados na cultura de milho com relação ao teor de clorofila na pesquisa de Viña et al. (2004). Devido a sua sensibilidade a clorofila, o índice permitiu espacializar de forma esperada áreas com plantas daninhas mais densas e menos densas em solos para pré-plantio.

O solo exposto foi representado pela cor vermelha e as plantas daninhas mais densas pela cor verde e as menos densas pela cor amarela. De acordo com a pesquisa, a aplicação à taxa variável traria bons resultados, tal que no mapa ficou claro que as plantas daninhas são uma minoria em relação ao solo exposto, o que leva a inferir que as aplicações direcionadas diminuiriam para a metade ou menos ainda os custos com o herbicida, já que de forma tradicional é aplicado por toda a lavoura. Ainda com estes resultados, uma vazão maior poderia ser aplicada as classes de plantas daninhas com mais biomassa (verde) e uma vazão menor as plantas daninhas com menor índice de área foliar (amarelo) (Figura 3). Apesar da ocorrência de sombras em algumas áreas do pequeno talhão, os resultados ainda foram satisfatórios.

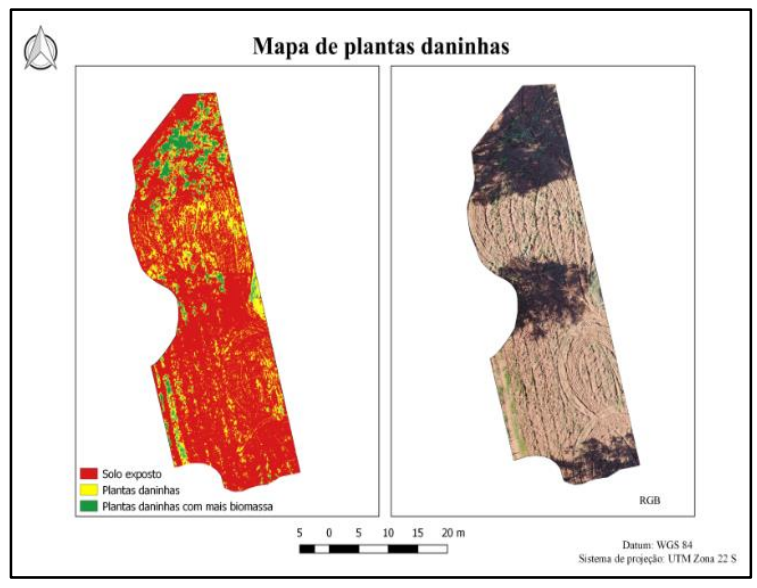

Figura 3 - Plantas daninhas. Fonte: $\mathrm{O}$ autor

\section{CONCLUSÕES}

Através da aplicação de herbicida com o mapa de plantas daninhas, é possível realizar a aplicação à taxa variável a fim de minimizar os custos, já que onde só possui solo exposto a aplicação não é efetivada. Além disso, o mapa também permite inferir os locais que necessitam de uma vazão maior em função da quantidade de biomassa das plantas daninhas. Quanto à identificação das falhas de plantio e contagem de plantas, ela permite aumentar a produtividade e realizar planejamentos de replantio.

\section{REFERÊNCIAS}

ALVES, M, O.; FERREIRA, R, V.; GALLIS, R, B, A. Otimização na Identificação de falhas de Plantio na Cana-de-açúcar com Uso de Geoprocessamento. X Congresso Brasileiro de Agroinformática, 2015.

BASSO, B.; DUMONT, B.; CAMMARANO, D.; PEZZUOLO, A.; MARINELLO, F.; SARTORI, L. Environmental and economic benefits of variable rate nitrogen fertilization in a nitrate vulnerable zone. Sci. Total Environ. 2016, 545-546, 227-235.

CHRISTENSEN, S.; SOGAARD, HT; KUDSK, P.; NORREMARK, M.; LUND, I.; NADIMI, ES; JORGENSEN, R. Site-specific weed control technologies. Weed Res. 2009, 49, 233-241.

FLEMING, KL; WESTFALL, DG; WIENS, DW; BRODAHL, MC Evaluating farmer defined management zone maps for variable rate fertilizer application. Precis. Agric. 2000, 2, 201-215.

FOLEY, JA; RAMANKUTTYY, N.; BRAUMAN, KA; CASSIDY, ES; GERBER, JS; JOHNSTON, M.; MUELLER, ND; O'CONNELL, C.; RAY, DK; 
WEST, PC; ET AL. Solutions for a cultivated planet. Nature 2011, 478, 337-342.
VIÑA, A.; GITELSON, A, A.; RUNDQUIST, D, C. et al. Monitoring maize (Zea mays L.) phenology with remote sensing. Agronomy Journal, v.96, p.1139-1147, 2004. 